\title{
Laparoscopic robotic-assisted gastrointestinal surgery: a Geneva experience
}

\author{
Claudio Soravia $\cdot$ Ian Schwieger · Jacques-Alain Witzig · Frank-Alain Wassmer • \\ Thierry Vedrenne $\cdot$ Pierre Sutter $\cdot$ Jean-Philippe Dufour $\cdot$ Yves Racloz
}

Published online: 27 February 2008

(C) Springer-Verlag London Ltd 2008

Erratum to: J Robotic Surg (2008) 1:291-295

DOI 10.1007/s11701-007-0058-2

The research described in this paper relates to over 400 cases performed at the Clinique Générale-Beaulieu, Geneva, Switzerland. The authors would like to modify the title of this paper to "Laparoscopic robotic-assisted gastrointestinal surgery: a Geneva experience" to reflect where the research was carried out.
The authors would also like to clarify that their affiliations and contact details are as given here, not as originally published.

The online version of the original article can be found under doi:10.1007/s11701-007-0058-2.

C. Soravia ( $\square)$ · J.-A. Witzig · F.-A. Wassmer · Y. Racloz Laparoscopic Robotic Surgery, Clinique Générale-Beaulieu, Geneva, Switzerland

e-mail: csoravia@hin.ch

I. Schwieger · P. Sutter · J.-P. Dufour

Anesthesiology, Clinique Générale-Beaulieu, Geneva,

Switzerland

T. Vedrenne

Medical Computing, Clinique Générale-Beaulieu, Geneva,

Switzerland

C. Soravia · I. Schwieger

University of Geneva, Geneva, Switzerland 